Article

\title{
Sustainable Closed-Loop Mask Supply Chain Network Design Using Mathematical Modeling and a Fuzzy Multi-Objective Approach
}

\author{
Roy Setiawan ${ }^{1, *}$, Rabia Salman ${ }^{2}$, Bari Galimovich Khairov ${ }^{3}$, Valeriy Vasilyevich Karpov ${ }^{4}$, \\ Svetlana Dmitrievna Danshina ${ }^{5}$, Lidia Vladimirovna Vasyutkina ${ }^{6}$, Natalia Alekseevna Prodanova ${ }^{7}$, \\ Viacheslav Zhenzhebir ${ }^{8}$, Evgeny Nuyanzin ${ }^{9}$, Nadezhda Kapustina ${ }^{4}$ and Ali Hasanzadeh Kalajahi ${ }^{10}$
}

check for

updates

Citation: Setiawan, R.; Salman, R.;

Khairov, B.G.; Karpov, V.V.;

Dmitrievna Danshina, S.;

Vladimirovna Vasyutkina, L.;

Alekseevna Prodanova, N.;

Zhenzhebir, V.; Nuyanzin, E.;

Kapustina, N.; et al. Sustainable

Closed-Loop Mask Supply Chain

Network Design Using Mathematical

Modeling and a Fuzzy

Multi-Objective Approach.

Sustainability 2021, 13, 5353. https://

doi.org/10.3390/su13105353

Academic Editor: Erfan

Babaee Tirkolaee

Received: 6 April 2021

Accepted: 24 April 2021

Published: 11 May 2021

Publisher's Note: MDPI stays neutral with regard to jurisdictional claims in published maps and institutional affiliations.

Copyright: (c) 2021 by the authors. Licensee MDPI, Basel, Switzerland. This article is an open access article distributed under the terms and conditions of the Creative Commons Attribution (CC BY) license (https:// creativecommons.org/licenses/by/ $4.0 /)$.
1 Department of Management, Faculty of Business and Economics, Universitas Kristen Petra, Surabaya 60236, Indonesia

2 Postdoctoral Fellow, School of Management, Universiti Sains, Penang 11800, Malaysia; aarabiaa@gmail.com

3 Rectorate, Siberian State University of Telecommunications and Information Sciences, 86 Kirov str., 630102 Novosibirsk, Russia; bari.khairov@yandex.ru

4 Department of Economics and Management, Financial University under the Government of the Russian Federation, 49 Leningradsky Av., 125993 Moscow, Russia; valeriyv.karpov@bk.ru (V.V.K.); NadezhdaKapustina@gmail.com (N.K.)

5 Faculty of Dentistry, Sechenov First Moscow State Medical University, 119991 Moscow, Russia; svetti.danshina@inbox.ru

6 Department of Engineering, Bauman Moscow State Technical University, 105005 Moscow, Russia; LidiaVladimirovnaVASYUTKINA@gmail.com

7 Department of Economics, Plekhanov Russian University of Economics Moscow, 105005 Moscow, Russia; prodanova-00@mail.ru

8 Department of Economics, Plekhanov Russian University of Economics, Stremyanny Lane 36, 117997 Moscow, Russia; viacheslavzhenzhebir@gmail.com

9 Department of Economcis, National Research Mordovia State University, 68 Bolshevistskaya Str., Saransk, 430005 Mordovia, Russia; evgenynuyanzin@gmail.com

10 Faculty of Materials Science and Engineering Najafabad Branch, Islamic Azad University Tehran North Branch, Tehran 1651153311, Iran; alihasanzadehkalajahi@gmail.com

* Correspondence: roy@petra.ac.id

Abstract: The outbreak of the deadly coronavirus, which is increasing the number of victims every day, has created many changes in today's world. The use of various masks is the most important social tool against this virus. Given the importance of rapid and quality supply of masks in the current situation, it is necessary to study supply chain in particular. In this research, the design of a closed chain supply chain network for different types of masks is assessed. The studied supply chain includes suppliers, manufacturers, distributors, and retailers in the forward flow and collection centers, separate centers, recycling centers, and disposal centers in the backward flow. In this regard, a multi-objective mathematical model with the objectives of increasing the total profit and reducing the total environmental impact, and maximizing social responsibility is presented. The optimization of this mathematical model has been done using a fuzzy optimization approach in GAMS software. The results of this study show that maximizing the total profit and minimizing the environmental effects and maximizing social responsibility are in contrast to each other. In addition, the sensitivity analysis indicated that the customers' demand can affect all aspects of the sustainable supply chain simultaneously.

Keywords: mask supply chain; sustainable supply chain network design; closed-loop supply chain; fuzzy optimization approach; environmental effects; social responsibility

\section{Introduction}

A supply chain is a series of activities, including production, distribution, and purchase, according to which a product or service (value) is transferred to the end customer. 
On the other hand, a closed-loop supply chain encompasses production, maintenance, and distribution activities in the principal direction from the supplier of raw materials to the final customer, as well as activities of collection and transfer of recycled goods from the customer [1]. Today, no company can neglect supply chain management and expect to survive. In today's competitive market, production and economic agencies have felt the need for the management and supervision of resources and related pillars outside the organization in addition to dealing with internal resources. This is mainly carried out to achieve a competitive advantage and earn a larger share of the market while considering environmental issues. Accordingly, activities such as supply and demand planning, material production, product planning and production, product maintenance services, inventory control, distribution, delivery, and service to customers, which were all performed at the company level in the past, are now included at the supply chain level. The key issue in a supply chain is the management and coordinated control of all activities.

The year 2020 started with an extreme shortage in medical equipment at global level due to the outbreak of the COVID-19 virus [2], which showed the importance of a supply chain for personal protective equipment and virus test kits across the world. In addition, supply chain management can be efficient in supplying specific types of products [3]. The causes of the shortage of surgical and N95 masks during the global outbreak of COVID19 were evaluated in the Report of the World Organization for Economic Development and Cooperation [4]. The report emphasizes the necessity of cooperation of countries in supplying this product in emergencies and the formation of global supply chains. A review of the literature revealed that few studies have specifically modeled and analyzed a closed-loop mask supply chain. Given the growing importance of supplying medical masks and the necessity of recycling used masks, it is clear that the present study can play an important role in the optimization of the production and distribution process of the product.

On the other hand, the issue of sustainability is one of the most important research areas in the field of supply chain network design [5]. Sustainability refers to three aspects: economic, social, and environmental. Designing a sustainable supply chain network while considering environmental pollutions is one of the most important concepts in supply chain management [6]. Moreover, the social aspect of a sustainable supply chain refers to the job opportunities in supply chain [7].

Pahleven et al. in 2020 proposed a mathematical model for the sustainable and closedloop supply chain [8]. Waltho et al. in 2019 reviewed articles on the design of a green supply chain. These scholars mainly emphasized the adjustment of supply chain policies to environmental goals. In addition, they proposed that quantitative approaches be developed to measure greenhouse gas emissions [9].

In a research paper by Mohtashami et al. in 2020, a closed-loop supply chain to decrease the negative environmental effects is presented. According to these researchers, the amount of energy consumption is one of the most important factors for negative environmental effects. In addition, focusing on product recycling and reproducing defective products was used as an efficient approach to reduce these effects [10]. In the latest research, Lee et al. in 2021 designed a two-level green supply chain, for which they presented a new mathematical model, in which pricing policies and profit-sharing between chain members were also optimized. Taking customer demand uncertainty into account, the results showed that the benefits of chain members in terms of sharing benefits outweigh the non-sharing mode [11]. In another study, Habib et al. in 2021 evaluated orientation to sustainability in supply chains based on environmental components. In this research, a conceptual model was presented, where sustainability was assessed using two approaches of market orientation and knowledge management. According to the results of implementation in the textile industry, having strategies based on environmental indicators is one of the most important tools in developing supply chain sustainability [12]. In the latest research, Sarkar et al. in 2021 examined the environmental impact of using a sustainable supply chain network. In this research, quality improvement through the study of product life 
was introduced as an efficient approach in designing a sustainable supply chain network with minimal adverse environmental impacts [13].

Kungwalsong et al. in 2021 proposed two-stage scholastic programming for the supply chain network design [14]. Giuffrida and Mangiaracina studied the green supply chain network design and provided a comprehensive literature review in this field [15]. Sirilertsuwan et al. studied the multi-tier supply chain and optimized location and distribution in this supply chain [16]. Zhou et al. proposed a fuzzy two-objective mathematical model for the closed-loop supply chain network design [17].

The present study focuses on mask supply chain design not only from an economic point of view but also from an economic perspective along with environmental issues. In addition, we present a new mathematical model with a corresponding solution method for optimizing the mask supply chain.

\section{Materials and Methods}

The overall structure of the sustainable closed-loop mask supply chain is presented in Figure 1, where the leading current considers reverse flow and their interactions simultaneously. Several types of masks with the features of re-use, recyclability, and disposable are considered in this supply chain. In addition, the network is constructed as a supply chain in five progressive stages and five reverse stages. In this research, a multi-objective mathematical model is presented to design a closed-loop mask supply chain, the first and second objectives of which are to increase the total profit of the supply chain and decrease unfavorable environmental effects, respectively. The third objective is the maximization of social responsibility. A proposed solution method based on fuzzy programming using the $\varepsilon$-constraint technique is presented. One of the advantages of the $\varepsilon$-constraint technique is generating all efficient solutions by producing ineffective solutions, which helps the decision-maker to see the complete solution and choose the best option. Moreover, the solution obtained by the $\varepsilon$-constraint technique is not affected by the objective function scale. This model uses an efficient solution that can create balanced solutions by creating a proper balance between environmental and economic goals.

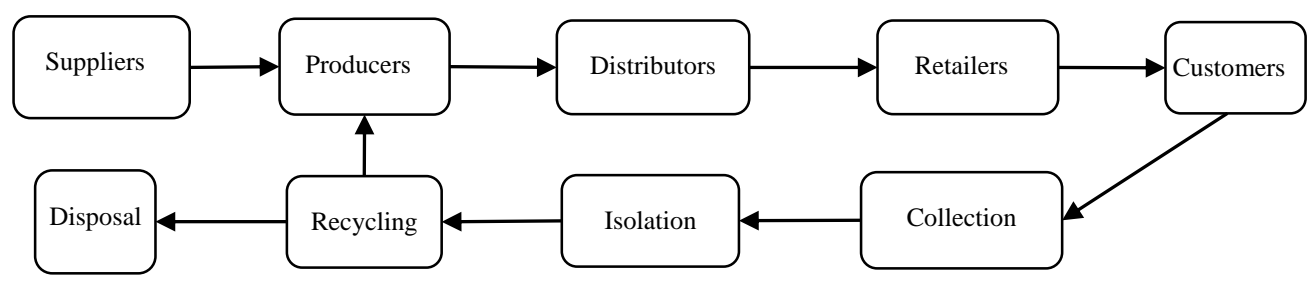

Figure 1. Proposed closed-loop supply chain framework.

Economically, an organization should maximize its final profit while satisfying the demand of the factory production department [18-21]. To this end, the organization should know how many masks should be used in the reconstruction process and how many new raw materials should be purchased from international suppliers. In this problem, there are several customer areas, collection centers, separation centers, and recycling centers. Therefore, not only does the model determines the number of masks and raw materials under process, but it also decides about the establishment of an installation center. Furthermore, the model determines the number of raw materials purchased from an international supplier. Environmentally, there are two main factors that exert unfavorable environmental impacts, including carbon generated by transporting a variety of masks and unfavorable effects of disposal of used masks. Accordingly, and considering the importance of environmental impacts in the mask supply chain, the reduction of adverse environmental impacts along with the economic objective function is simultaneously optimized. In addition, social responsibility is considered as total created jobs in the supply chain. 
and collection cost at the collection center. The next two steps include the cost of processing and commissioning the separation centers. The cost of transportation from different centers of the facility is presented in the last stage-i.e., the fifth stage.

$$
\begin{aligned}
\operatorname{Max} Z_{1}= & \sum_{j} P F_{j}\left(p_{j}+\sum_{m} a_{j m}\right)+\sum_{n, i} R P_{i} \cdot y_{i n}-\sum_{k, i} P C_{i k} \cdot s_{i k}-\sum_{j, c, m} C C_{j m} \cdot c_{j c m}-\sum_{m, j} S C_{j m} \cdot b_{j m}-\sum_{m, j} U C_{j m} \cdot a_{j m} \\
& -\sum_{n, i} D C_{i n} \cdot t_{i n}-\sum_{n, j} S D_{j n} \cdot v_{j n}-\sum_{l, i} R C_{i l} \cdot f_{i l}-\sum_{l, i} S R_{i l} \cdot u_{i l}-\sum_{n, i} W D C_{i} \cdot w_{i n}-\sum_{j, c, m} R F_{j m} \cdot c_{j c m} \\
& -\sum_{j, c, m} T C C_{j c m} \cdot c_{j c m}-\sum_{j, m, n} T C D_{j m n} \cdot r_{j m n}-\sum_{i, n, l} T C R_{i n l} \cdot f_{i n l}-\sum_{i, l} T C P_{i l} \cdot f_{i l}-\sum_{j, m} T C U_{j m} \cdot a_{j m}
\end{aligned}
$$

The second objective is to minimize the environmental effect of transportation in the reverse supply chain regarding carbon footprint (Equation (2)). Different parts of the second objective function show carbon emission from the customer to the collection center, from the collection center to the part isolation center, from the isolation center to the recycling center, and from the recycling center to the factory. In Equation (3), the total number of created jobs by establishing recycle and collection centers is calculated.

$$
\begin{gathered}
\operatorname{Min} \mathrm{Z}_{2}=\sum_{j, c, m} E T C_{j c m} \cdot c_{j c m}+\sum_{j, m, n} E T D_{j m n} \cdot r_{j m n}+\sum_{i, n, l} E T R_{i n l} \cdot f_{i n l}+\sum_{i, l} E T P_{i l} \cdot f_{i l} \\
\operatorname{Max} Z_{3}=\sum_{i, l} u_{i l} \cdot J u_{l}+\sum_{j, m} b_{j m} . J b_{m}
\end{gathered}
$$

Constraint (4) guarantees that demand for each mask is met by the sum of new products and reused masks. In addition, constraints (5-7) show the current balance in collection centers, isolation centers, and reconstruction centers. Constraints (8-10) calculate the number of raw materials at the isolation center and reconstruction center and the number of masks in isolation centers. Constraint (11) estimates the number of masks at each collection center from different customer regions. Moreover, constraints (12-15) show the maximum limit on the number of masks collected, the number of reuses, the amount of reconstituted raw materials, and the amount of recyclable raw materials. Constraints (16-19) guarantee the capacity limits for collection centers, isolation centers, recycling centers, and factories. In addition, constraint (20) guarantees the maximum and minimum capacity of international supplies, while constraints (21) and (22) are related to the type of decision variables in the model. It is notable that all decision variables are positive.

$$
\begin{array}{cc}
\sum_{c} D E_{j c}=p_{j}+\sum_{m} a_{j m} & \forall j \\
c_{j m}=a_{j m}+\sum_{n} a_{j m n} & \forall j, m \\
t_{i n}=y_{i n}+w_{i n}+\sum_{i} f_{i n l} & \forall i, n \\
\sum_{j} Q_{i j} \cdot p_{j}=\sum_{l} f_{i l}+\sum_{k} s_{i k} & \forall i \\
t_{i n}=\sum_{m} \sum_{j} Q_{i j} \cdot r_{j m n} & \forall i, n \\
f_{i l}=\sum_{n} f_{i n l} & \forall i, l \\
r_{j n}=\sum_{m} r_{j m n} & \forall j, n \\
c_{j m}=\sum_{c} c_{j c m} & \forall j, m \\
\sum_{m} c_{j c m} \leq \eta_{j} . D E_{j c} & \forall j, c
\end{array}
$$




$$
\begin{array}{lc}
a_{j m} \leq \gamma_{j} \cdot c_{j m} & \forall j, m \\
\sum_{l} f_{i n l} \leq \lambda_{i} \cdot t_{i n} & \forall i, n \\
y_{i n} \leq \beta_{i} \cdot T_{i n} & \forall i, n \\
c_{j m} \leq M C_{j m} \cdot b_{j m} & \forall j, m \\
\sum_{m} r_{j m n} \leq M D_{j n} \cdot v_{j n} & \forall j, n \\
\sum_{n} f_{i n l} \leq M R_{i l} \cdot u_{i l} & \forall i, l \\
p_{j} \leq M R_{j} & \forall j \\
M N S_{k} \leq \sum_{i} s_{i k} \leq M X S_{k} & \forall k \\
b_{j m}, v, u_{i l} \in\{0,1\} & \forall i, j, m, n, l
\end{array} \quad \forall i, j, m, n, l, k
$$

This section presents the mathematical model's solution based on its multi-objective nature. This solution is inspired by the fuzzy multi-objective optimization approach and attempts to express changes in each of the objective functions in the form of a fuzzy membership function. Then, one of these membership functions is put in the constraints to control its value and the other in the target function to get the best value. In other words, the final part of this solution is similar to the technique of Epsilon-constraint, which exploits two concepts of $\alpha$-optimal and $\alpha$-nadir. In this regard, $\alpha$-optimal refers to the best possible value for each of the objective functions and the value of the corresponding decision variables, which are estimated for each of the objective functions based on Equation (23).

$$
\begin{aligned}
& Z_{1}^{\alpha-o p t i m a l}=\operatorname{Max}\left\{Z_{1} \mid x \in F(x)\right\} \\
& Z_{2}^{\alpha-o p t i m a l}=\operatorname{Min}\left\{Z_{2} \mid x \in F(x)\right\} \\
& Z_{3}^{\alpha-o p t i m a l}=\operatorname{Max}\left\{Z_{3} \mid x \in F(x)\right\}
\end{aligned}
$$

where $F(x)$ is the series of justifiable solution to the problem, which includes the constraints of the equivalent model. In addition, the concept of $\alpha$-nadir refers to the worst value allowed for each of the objective functions, if the other objective is at its best (in its value). In other words, it is estimated for each of the objectives based on Equation (24).

$$
\begin{aligned}
Z_{1}^{\alpha-n a d i r} & =\operatorname{Max}\left\{Z_{1} \mid Z_{2} \leq Z_{2}^{\alpha-\text { optimal }} \& x \in F(x)\right\} \\
Z_{2}^{\alpha-n a d i r} & =\operatorname{Min}\left\{Z_{2} \mid Z_{1} \geq Z_{1}^{\alpha-\text { optimal }} \& x \in F(x)\right\} \\
Z_{3}^{\alpha-n a d i r} & =\operatorname{Maz} x\left\{Z_{3} \mid Z_{1} \geq Z_{1}^{\alpha-\text { optimal }} \& x \in F(x)\right\}
\end{aligned}
$$

After defining the principles and concepts used in this method, the steps of the proposed solution method are described below.

- Step 1: Determining the minimum degree of possibility of the decision vector (i.e., $\alpha$ ) to decide on the importance of each objective;

- Step 2: Determining $\alpha$-optimal and $\alpha$-nadir solutions for each objective function on the efficient set;

- Step 3: Fuzzy linear membership function is determined for each objective function, as shown below, where $\mu_{1}(x)$ and $\mu_{2}(x)$ show the fuzzy membership degree for the first and second objectives. 


$$
\begin{aligned}
& \mu_{1}(x)=\left\{\begin{array}{cc}
1 & Z_{1}>Z_{1}^{\alpha-o p t i m a l} \\
0 & Z_{1}<Z_{1}^{\alpha-n a d i r} \\
\frac{Z_{1}-Z_{1}^{\alpha-n a d i r}}{Z_{1}^{\alpha-o p t i m a l}-Z_{1}^{\alpha-n a d i r}} & \text { otherwise }
\end{array}\right. \\
& \mu_{2}(x)=\left\{\begin{array}{cc}
1 & Z_{2}<Z_{2}^{\alpha-o p t i m a l} \\
0 & Z_{2}>Z_{2}^{\alpha-n a d i r} \\
\frac{Z_{2}^{\alpha-n a d i r}-Z_{2}}{Z_{2}^{\alpha-n a d i r}-Z_{2}^{\alpha-o p t i m a l ~}} & \text { otherwise }
\end{array}\right. \\
& \mu_{3}(x)=\left\{\begin{array}{cc}
Z_{3}>Z_{3}^{\alpha-o p t i m a l} \\
0 & Z_{3}<Z_{3}^{\alpha-n a d i r} \\
\frac{Z_{3}-Z_{3}^{\alpha-n a d i r}}{Z_{3}^{\alpha-o p t i m a l}-Z_{3}^{\alpha-n a d i r}} & \text { otherwise }
\end{array}\right.
\end{aligned}
$$

- $\quad$ Step 4: Converting the equivalent multi-objective model into a single-objective model based on the $\varepsilon$-constraint method, which is carried out according to Equation (26).

$$
\max \left\{\mu_{1}(x) \mid \mu_{2}(x) \geq \varepsilon, \mu_{3}(x) \geq \varepsilon, \quad x \in F(x), \quad 0 \leq \varepsilon \leq 1\right\}
$$

- In the mentioned formula, the satisfaction degree of the performance of the first objective is maintained in the objective function, and the degree of satisfaction of the second objective function is used as a side constraint. Nevertheless, each degree of satisfaction can be used as a side constraint or objective function.

- Step 5: The value of $\varepsilon$ in Equation (26) systematically changes between zero and one to produce Pareto optimal in the entire efficient set.

- Step 6: If the decision maker is satisfied with one of the product solutions, the process will be stopped, and the accepted solution will be selected as the final decision. Otherwise, the most preferred line segment will be selected, and the decision-maker will move on to step five to change the value of $\varepsilon$ in the new constraint and generate a new Pareto optimal. In addition, the decision-maker might be willing to change the value of $\alpha$ in some cases, and if the $\alpha$ value changes, the algorithm must be restarted from step one.

\section{Results and Discussion}

The input data for the generation of the sample problem are obtained from a mask production factory near Isfahan, Iran. In this regard, we consider two types of three-layer medical and N95 masks for marketing and three types of raw materials of fabric, retainers, and breathable filters for mask production. In the relevant supply chain structure, there are three collection centers, two isolation centers, two recycling centers, three raw material suppliers, and one disposal center. Other parameters of the problem are presented in Table 4, where the symbol of Unif shows the uniform distribution. The cost of transportation on different routes is obtained by multiplying the distance traveled into the cost of transporting one unit of goods per kilometer. For instance, we will have TCC_jcm $=(T C C)^{\sim} \_\mathrm{jcm} . \mathrm{D} \_\mathrm{cm}$ and TCP_il $=(\mathrm{TCP})^{\sim}$ _il.D_l, where the parameters of D_l and D_cm show the distances between the production center and the factory, as well as the distance between the customer center and the collection center.

Table 4. Input data for generation of sample problem.

\begin{tabular}{ll}
\hline$\widetilde{T C C}_{j c m}=\operatorname{Unif}(0.4,0.8)$ & $\widetilde{T C P}_{i l}=\operatorname{Unif}(0.3,0.6)$ \\
$D_{c m}=\operatorname{Unif}(3,6)$ & $D_{m n}=\operatorname{Unif}(18,25)$ \\
$D_{n l}=(8,12)$ & $D_{l}=\operatorname{Unif}(6,8)$ \\
$M X S_{k}=\operatorname{Unif}(4000,5000)$ & $M N S_{k}=100$ \\
$M D_{j n}=\operatorname{Unif}(1000,2000)$ & $M R_{i l}=\operatorname{Unif}(600,1000)$ \\
$n_{j}=0.7$ & $\gamma_{j}=0.2$ \\
$\lambda_{i}=0.7$ & $\beta_{i}=0.3$ \\
\hline
\end{tabular}


To analyze the performance of the proposed model, the model is coded and solved in GAMS software. In this respect, satisfaction with economic objectives is preserved in the objective function, and satisfaction with environmental objectives is used as a side constraint. The Pareto optimal solution is generated using the modified $\varepsilon$-constraint method at 0.5 degrees of possibility $\left(\alpha_{\text {level }}=0.5\right)$. Results obtained from the model are exhibited in Figures 2 and 3, according to which the two objectives of maximization of total profit and minimization of environmental impacts are in opposition to each other since the decrease of environmental effects leads to increased overall costs, thereby decreasing the total profit of the organization. The difference between the values of the economic objective function in the Diagram indicates the price paid for environmental protection, which means the organization's economic profit loss for environmental protection. The index has a dual significance since it can be used by organizations as a quantitative index to show their efforts made to protect the environment. It can also be used as a basis by the government to motivate organizations.

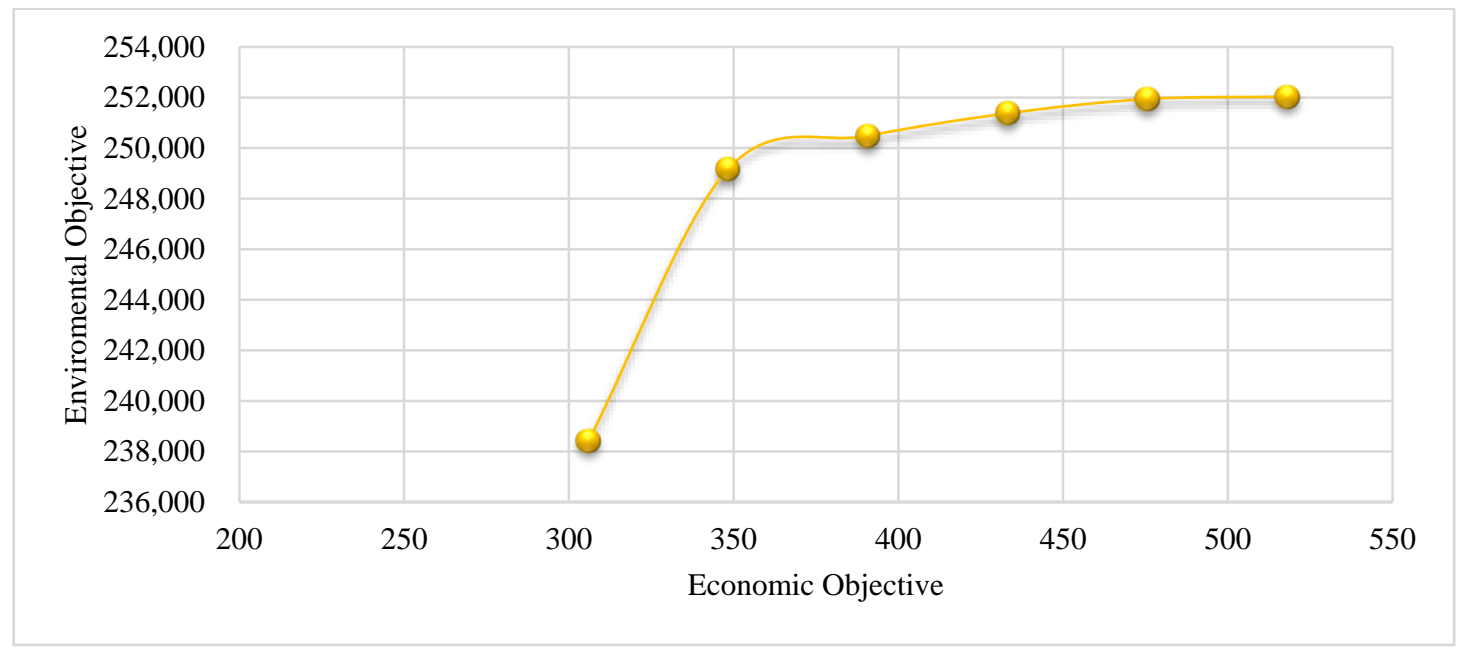

Figure 2. Results of the proposed method in the first and second objectives for the values of objective functions.

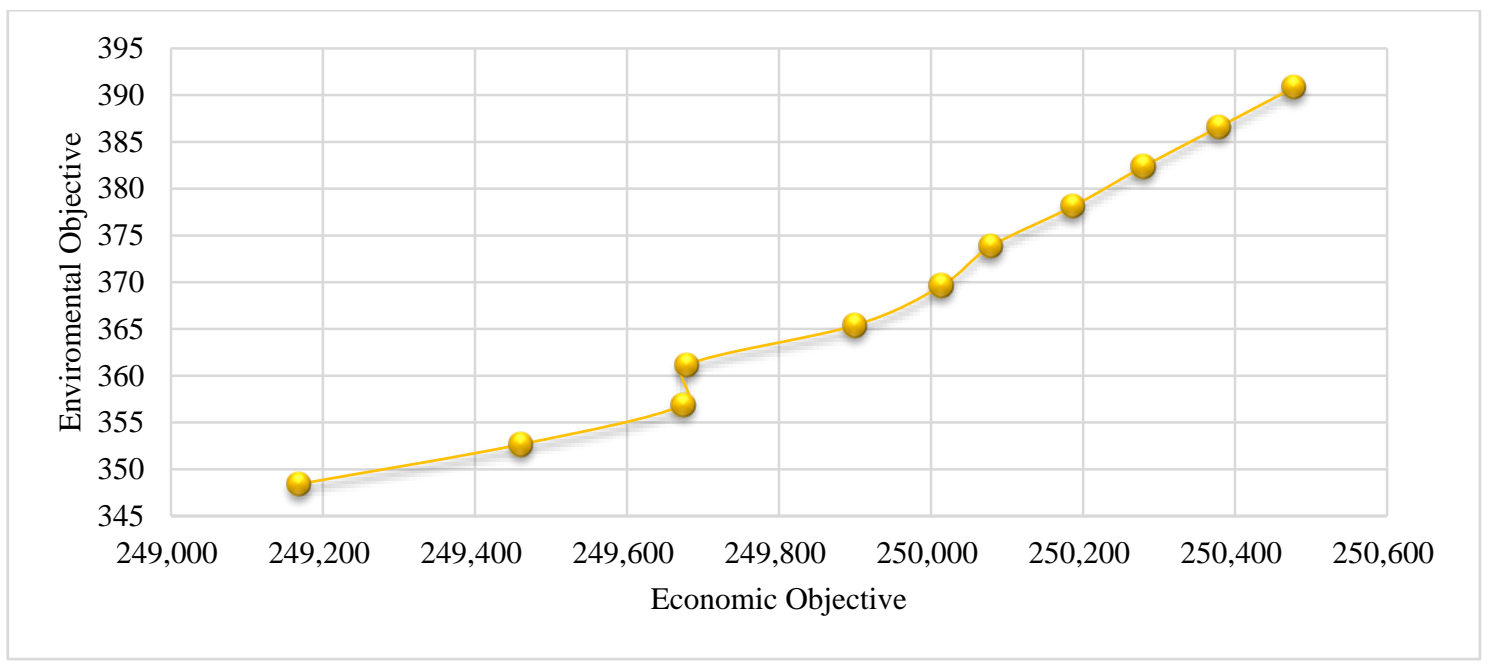

Figure 3. Results of the proposed method in the first and second objectives for the degree of satisfaction.

In the first repetition, the decision-maker can adjust the values of Epsilon in the range of $0-1$. Therefore, the decision-maker starts with a wide range to quickly cover a wide range of Pareto solutions. Nevertheless, the decision-maker may be interested in choosing the 
final solution through accurate adjustment using denser points in the following repetitions. The primary solution series in the first repetition is shown in Figures $2-4$ using $\varepsilon$ in the range of $0-1$ and a 0.2 growth. The results related to the degree of satisfaction with the objectives show that the level of satisfaction with economic performance decreases with increasing the level of satisfaction with environmental performance and social responsibility. Following that, the proposed algorithm is implemented in the second repetition as well. In the second repetition, the Epsilon parameter fluctuates between 0.6 and 0.8 , and the value of the three objective functions and level of satisfaction at each Pareto point is determined. As observed in the outputs of the two steps, the designed Epsilon-delta definition of limit can present a complete series of different solutions. The points presented in Figures 2 and 3 are called the problem performance boundary. One of the advantages of mathematical models is their ability to assess changes and fluctuations in each of the proposed parameters and their impact on the final output of the model. In this study, this parameter is increased based on an uptrend, and its effect on different targets is examined to analyze the demand sensitivity of each mask. In addition, a coefficient of variation in the range of 0.9-1.5 is considered, and each time, the base demand value of each unit of product is multiplied by this value and then the model is implemented to determine its effect on the value of the total function. The relevant results are shown in Figures 5-7.

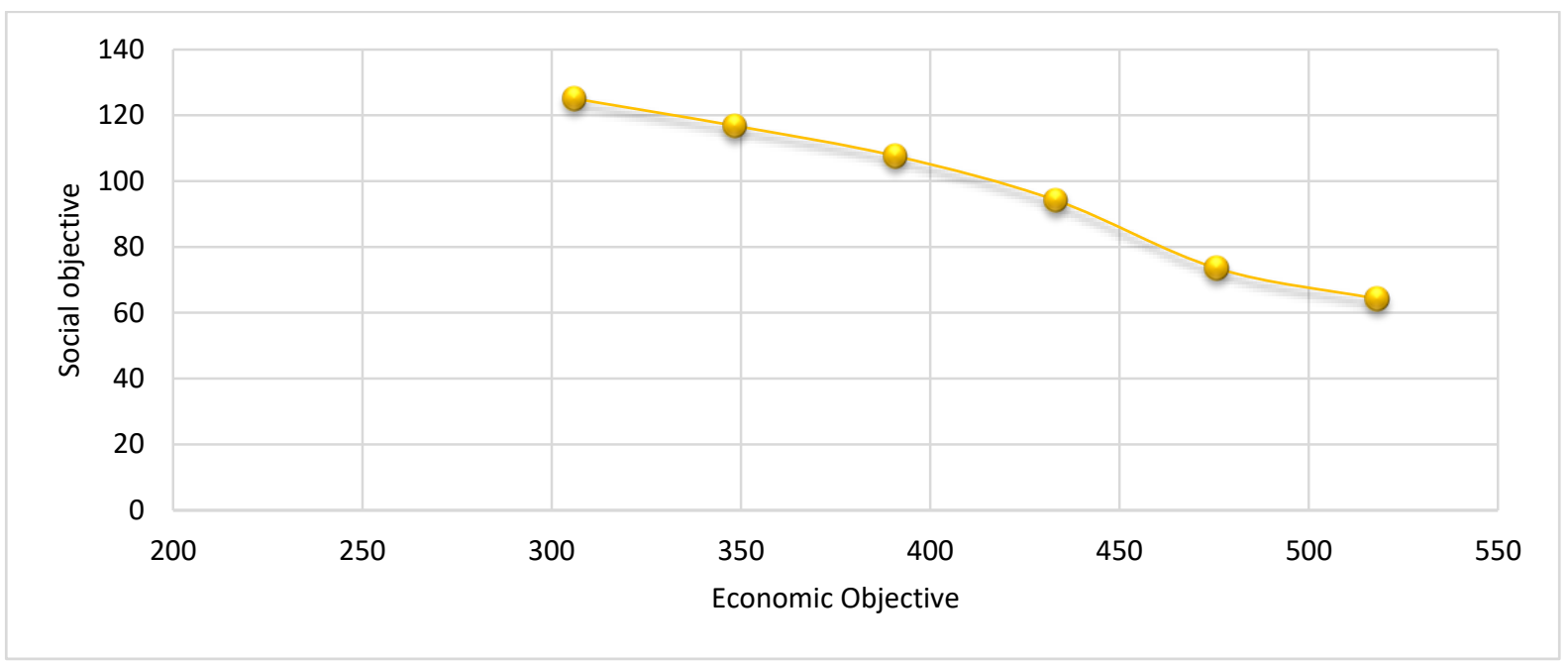

Figure 4. Results of the proposed method in the first and third objectives for the values of objective functions.

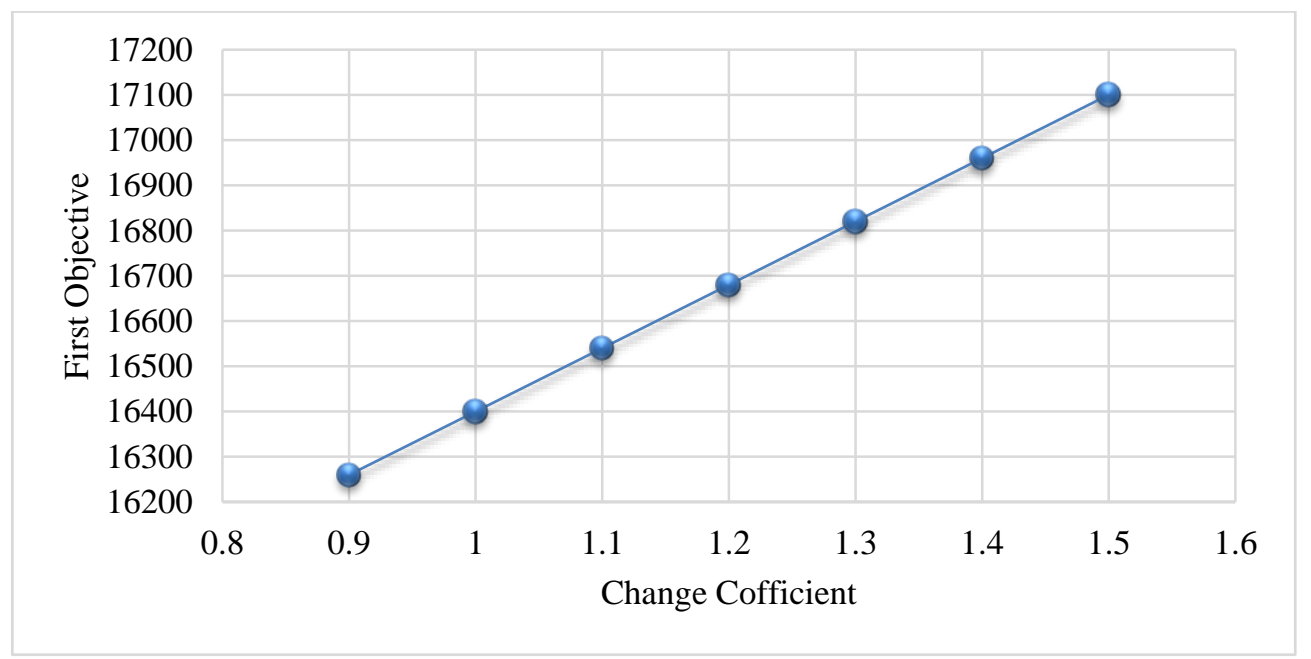

Figure 5. Results of analysis of the sensitivity of demand parameter on the economic objective function. 


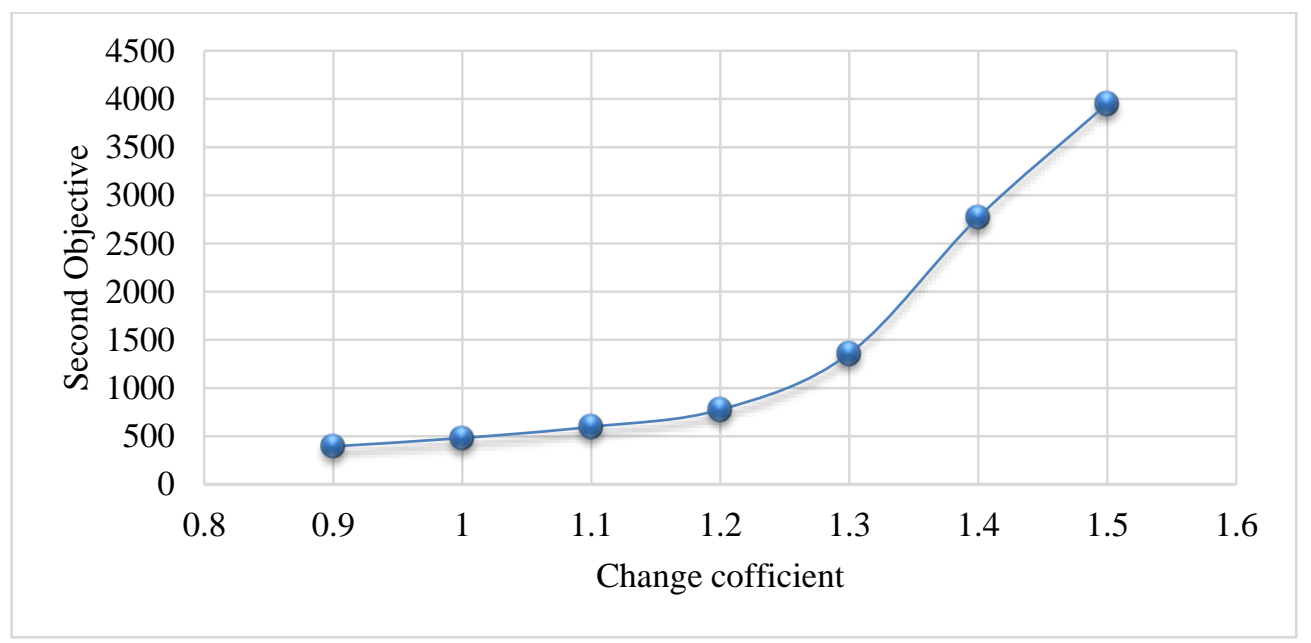

Figure 6. Results of analysis of the sensitivity of demand parameter on the environmental objective function.

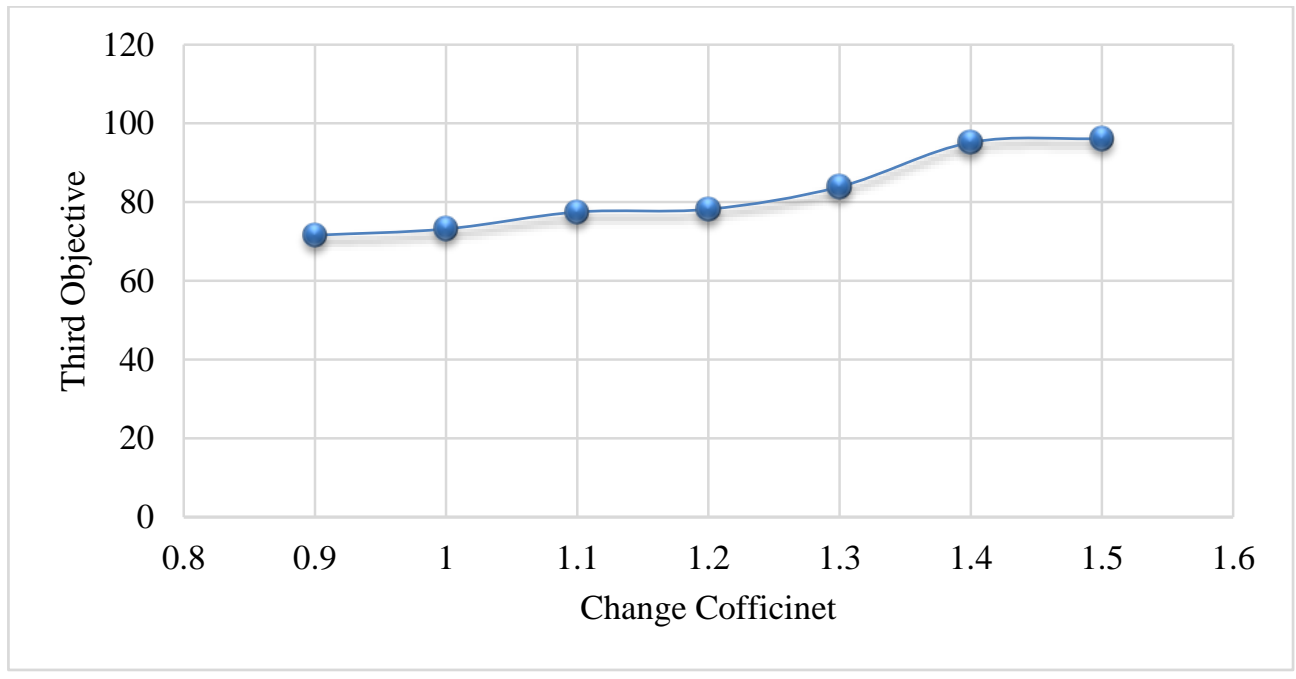

Figure 7. Results of analysis of the sensitivity of demand parameter on the environmental objective function.

As observed in Figures 5-7, as the demand for masks increases, so does the amount of economic as well as the environmental objective and social responsibility. Increasing the value of the first objective function has a linear relationship with increasing the coefficient of change, while the change in demand has a non-linear relationship with the second and third objective function. In other words, increased demand leads to a sharp increase in environmental pollution.

In addition, increasing the demand leads to having a small change in social responsibility. Therefore, in these circumstances, it can be claimed that the increase or decrease in demand has a very clear effect on the total costs of the supply chain, and given the linear relationship between them, it is easy to determine the increase or decrease in exchange for changing this parameter. It is not easy to make this level of detection of environmental pollution due to its nonlinear relationship and the relevant mathematical model must be re-optimized.

Accurate and in-depth analysis of the results obtained from the optimization of the mathematical model of the research shows that the field of sustainability for health products, including masks, is very important. On the other hand, reducing total costs is considered an important element in economic activities. Moreover, with the increasing prevalence of coronavirus, the importance of collecting and disposing of used masks has increased dramatically. Such chains are also expected to perform well socially. Comparisons were 
performed with Pahlevn et al. [7], and cleared that all aspects of sustainability can be adapted to new supply chain models in a correct way. Accordingly, the research results show that despite the severe conflict between different areas of sustainability, it is possible to provide a set of executive solutions for the production and distribution of masks in a way that is suitable both economically and environmentally and socially.

\section{Conclusions}

Given the outbreak of COVID-19 and the increasing use of masks, it seems necessary to plan for the production and recycling of this product in the form of a closed-loop supply chain in the current situation. The present study designed and optimized a multi-objective supply chain of masks based on environmental and economic factors. The first objective was to maximize the organization's profit by optimizing decisions on the number of recyclable masks and the number of raw materials purchased from international suppliers, as well as allocating locations to different installation centers. The second objective, however, was to minimize environmental impacts due to the carbon impact of transportation in the reverse supply chain. In the proposed framework, customer motivation is considered a social factor and is integrated with the economic goal function. The model covers multiple customer areas, collection centers, recycling centers, and international sources of raw materials, taking into account purchase, shipping, processing, and commissioning costs. With regard to the advantages of the interactive $\varepsilon$-constraint method, the method is used to calculate Pareto solutions for various levels of satisfaction with the environmental objective function's performance. According to the results, environmental and economic objectives in this supply chain are in conflict with each other, which necessitates having an appropriate method that satisfies both of these objectives to an acceptable level. With the increasing demand for masks, environmental conditions are rapidly deteriorating, which can lead to an environmental crisis if only economic goals are addressed. It is suggested that uncertainty in the demand for masks be added to the mathematical model as a fundamental and important assumption in future studies.

This research, like other researches, has different limitations. One of the most important limitations of this study is the lack of comprehensive information on the supply chain of COVID 19. It is also suggested that approaches such as robust optimization or spatial planning be used to address this uncertainty. It is also suggested that due to the complexity of the mathematical model, appropriate solution tools be provided to reduce the solution time, in which case the accelerated Benders decomposition algorithm or novel metaheuristic algorithms (e.g., red deer algorithm and social engineering optimizer) can be efficient.

Author Contributions: Conceptualization, R.S. (Roy Setiawan); methodology, R.S. (Rabia Salman); software, B.G.K.; validation, V.V.K.; formal analysis, S.D.D.; investigation, L.V.V.; resources, N.A.P.; data curation, V.Z.; writing - original draft preparation, E.N.; writing — review and editing, N.K.; visualization, A.H.K.; supervision, R.S. (Roy Setiawan); project administration, R.S. (Rabia Salman); funding acquisition, B.G.K. All authors have read and agreed to the published version of the manuscript.

Funding: This research received no external funding.

Institutional Review Board Statement: Not applicable.

Informed Consent Statement: Not applicable.

Data Availability Statement: Not applicable.

Conflicts of Interest: The authors declare no conflict of interest. 


\section{References}

1. Kumar, N.R.; Kumar, R.S. Closed loop supply chain management and reverse logistics-A literature re-view. Int. J. Eng. Res. Technol. 2013, 6, 455-468.

2. Rubin, G.D.; Ryerson, C.J.; Haramati, L.B.; Sverzellati, N.; Kanne, J.P.; Raoof, S.; Schluger, N.W.; Volpi, A.; Yim, J.-J.; Martin, I.B.K.; et al. The role of chest imaging in patient management during the COVID-19 pandemic: A multinational consensus statement from the Fleischner Society. Chest 2020, 158, 106-116. [CrossRef] [PubMed]

3. Sangaiah, A.K.; Tirkolaee, E.B.; Goli, A.; Dehnavi-Arani, S. Robust optimiza-tion and mixed-integer linear programming model for LNG supply chain planning problem. Soft Comput. 2020, 24, 7885-7905. [CrossRef]

4. Gereffi, G. What does the COVID-19 pandemic teach us about global value chains? The case of medical supplies. J. Int. Bus. Policy 2020, 3, 287-301. [CrossRef]

5. Kot, S. Sustainable Supply Chain Management in Small and Medium Enterprises. Sustainability 2018, 10, 1143. [CrossRef]

6. Al-Zabidi, A.; Rehman, A.U.; Alkahtani, M. An Approach to Assess Sustainable Supply Chain Agility for a Manufacturing Organization. Sustainability 2021, 13, 1752. [CrossRef]

7. Sánchez-Flores, R.B.; Cruz-Sotelo, S.E.; Ojeda-Benitez, S.; Ramírez-Barreto, M. Sustainable Supply Chain Management-A Literature Review on Emerging Economies. Sustainability 2020, 12, 6972. [CrossRef]

8. Pahlevan, S.M.; Hosseini, S.M.S.; Goli, A. Sustainable supply chain network design using prod-ucts' life cycle in the aluminum industry. Environ. Sci. Pollut. Res. 2021, 1-25. [CrossRef]

9. Waltho, C.; Elhedhli, S.; Gzara, F. Green supply chain network design: A review focused on policy adoption and emission quantification. Int. J. Prod. Econ. 2019, 208, 305-318. [CrossRef]

10. Mohtashami, Z.; Aghsami, A.; Jolai, F. A green closed loop supply chain design using queuing system for reducing environmental impact and energy consumption. J. Clean. Prod. 2020, 242, 118452. [CrossRef]

11. Li, P.; Rao, C.; Goh, M.; Yang, Z. Pricing strategies and profit coordination under a double echelon green supply chain. J. Clean. Prod. 2021, 278, 123694. [CrossRef]

12. Habib, M.; Bao, Y.; Nabi, N.; Dulal, M.; Asha, A.A.; Islam, M. Impact of Strategic Orientations on the Implementation of Green Supply Chain Management Practices and Sustaina-ble Firm Performance. Sustainability 2021, 13, 340. [CrossRef]

13. Sarkar, B.; Sarkar, M.; Ganguly, B.; Cárdenas-Barrón, L.E. Combined effects of carbon emission and production quality improvement for fixed lifetime products in a sustainable supply chain management. Int. J. Prod. Econ. 2021, 231, 107867. [CrossRef]

14. Kungwalsong, K.; Cheng, C.-Y.; Yuangyai, C.; Janjarassuk, U. Two-Stage Stochastic Program for Supply Chain Network Design under Facility Disruptions. Sustainability 2021, 13, 2596. [CrossRef]

15. Giuffrida, M.; Mangiaracina, R. Green Practices for Global Supply Chains in Diverse Indus-trial, Geographical, and Technological Settings: A Literature Review and Research Agen-da. Sustainability 2020, 12, 10151. [CrossRef]

16. Sirilertsuwan, P.; Thomassey, S.; Zeng, X. A Strategic Location Decision-Making Approach for Multi-Tier Supply Chain Sustainability. Sustainability 2020, 12, 8340. [CrossRef]

17. Zhou, J.; Xia, W.; Wang, K.; Li, H.; Zhang, Q. Fuzzy Bi-Objective Closed-Loop Supply Chain Network Design Problem with Multiple Recovery Options. Sustainability 2020, 12, 6770. [CrossRef]

18. Goli, A.; Zare, H.K.; Tavakkoli-Moghaddam, R.; Sadegheih, A. Multiobjective fuzzy mathematical model for a financially constrained closed-loop supply chain with labor employ-ment. Comput. Intell. 2020, 36, 4-34. [CrossRef]

19. Goli, A.; Davoodi, S.M.R. Coordination policy for production and delivery scheduling in the closed loop supply chain. Prod. Eng. 2018, 12, 621-631. [CrossRef]

20. Tirkolaee, E.B.; Goli, A.; Faridnia, A.; Soltani, M.; Weber, G.W. Mul-ti-objective optimization for the reliable pollution-routing problem with cross-dock selection using Pare-to-based algorithms. J. Clean. Prod. 2020, 276, 122927. [CrossRef]

21. Goli, A.; Tirkolaee, E.B.; Weber, G.-W. A Perishable Product Sustainable Supply Chain Network Design Problem with Lead Time and Customer Satisfaction using a Hybrid Whale-Genetic Algorithm. In Logistics Operations and Management for Recycling and Reuse; Springer: Berlin/Heidelberg, Germany, 2020; pp. 99-124. 